\title{
Nathalie syndrome
}

INSERM

\section{Source}

INSERM. (1999). Orphanet: an online rare disease and orphan drug data base. Nathalie syndrome. ORPHA:2663

Nathalie syndrome is characterised by deafness, cataract, muscular atrophy, skeletal abnormalities, growth retardation, underdeveloped secondary sexual characteristics, and electrocardiographic abnormalities. It has been described in a Dutch family: in three sisters (one named Nathalie) and their brother. 